\title{
Um Sentido para a Legitimidade do Direito: consciência, ação e interação
}

\section{Right a Sense the Legitimate of Law: awareness, action and interaction}

\author{
Samyra Naspolini Sanches \\ Universidade Nove de Julho, São Paulo - SP, Brasil \\ Universidade de Marília, Marília - SP, Brasil
}

Luciano Braz da Silva

Universidade do Oeste Paulista, Presidente Prudente - SP, Brasil

Resumo: o presente artigo pretende fazer uma releitura dos pressupostos de validade do direito tomando como campo de pesquisa o mundo da vida interpretado como esfera em que suscitam os discursos, os diálogos interpelativos e, em última instância, a esfera do exercício democrático. Diante das questões fenomenológicas de conteúdo político e econômico, que de algum modo atingem os direitos fundamentais, a validade do direito assume relevância quando as discussões ligadas aos direitos fundamentais do homem, sua dignidade e reconhecimento e sua compreensão do Estado Democrático de Direito, são rediscutidas, considerando, sobretudo, situações paradoxais que apontam pessoas, grupos e etnias que se encontram esquecidas pela sociedade. Este esboço é suficiente para levantar uma típica questão das sociedades modernas: como estabilizar, na perspectiva própria dos atores, a validade de uma ordem social legítima do ponto de vista do direito diante do multiculturalismo nacional e global?

Palavras-chave: Consciência. Ação. Deliberação. Ética.

\begin{abstract}
: this article intending to make a rereading of the right validity of assumptions takes as a research field the lifeworld interpreted as sphere where raises speeches, interpelativos dialogues, and ultimately, the sphere of democratic exercise. In front of phenomenological issues of political content and economic that somehow affect the fundamental rights, the validity of the right assumed importance as a central theme when discussions related to fundamental human rights, dignity and recognition and understanding of the democratic state law are revisited given, considering especially paradoxical situations that link people, groups and ethnicities forgotten the margins of society. This outline is enough to raise the typical problem of modern societies: how to stabilize in the proper perspective of the actors, the validity of a legitimate social order of the front right perspective the national multiculturalism and global?
\end{abstract}

Keywords: Conscience. Action. Deliberation. ethic

Recebido em: 26/11/2015

Revisado em: 09/03/2016

Aprovado em: 25/03/2016 


\section{Introdução}

Ao que tudo indica, dentre as reflexões teóricas da filosofia do direito abordadas por Jürgen Habermas, a teoria da ação comunicativa constitui-se em grande relevo como obra máxima do pensador da escola de Frankfurt. Nesse sentindo, refletir sobre uma possível racionalidade jurídica, que imprimiria a ele uma legitimidade, não seria possível se para isso não se pensasse a racionalidade estante nas esferas de ação integradas pelo agir comunicativo. O diagnóstico que aponta a presente crise do Estado Democrático de Direito e o das instituições que o integram denuncia que a presente crise resulta da penetração de formas de organização de caráter instrumental no interior da sociedade contemporânea, eliminando assim qualquer possibilidade de se pensar a figura do indivíduo como fonte e sujeito titular do exercício democrático participativo e deliberativo. Assim, a ideia de uma "colonização do mundo da vida" fornece tanto um diagnóstico das tendências de crise no mundo atual, como também as perspectivas não pessimistas de catástrofes anunciadas ou de resignação perante tais processos.

No tipo de validação que diz respeito à lei, a facticidade de sua imposição pelo Estado de Direito está imbricada com a força legitimadora de um procedimento legislativo cuja racionalidade tem de ser demonstrada, já que o sistema jurídico é o dispositivo que garante e assegura a liberdade. Há, então, uma peculiar ambivalência da lei em relação a seus destinatários e a expectativa de obediência; ela libera os primeiros para relacionar-se com ela em duas modalidades, de modo que eles podem considerar as normas como constrangimentos meramente factuais de sua liberdade, e assumir o risco calculado de consequências possíveis da eventual violação de regras; ou, então, podem cumprir os estatutos jurídicos a modo de uma atitude performativa, isto é, cumprindo-os com base no respeito pelos resultados de uma formação comum da vontade, com pretensão e exigência de legitimidade.

Trata-se, portanto, de uma interconexão conceitual que reflete, como o artigo busca demonstrar, na dialética entre igualdade legal e factual, suscitada primeiramente no paradigma jurídico do estado de bem-estar social, como resposta à compreensão liberal do direito. Em nossos dias, 
essa mesma dialética compele a uma autocompreensão procedimentalista da democracia constitucional. Para tanto, faz-se necessário considerar a divisão contemporânea das esferas de autonomia, pelas quais transitam sujeitos de direito: distinguindo o âmbito da autonomia pública, fundada no princípio da soberania popular, com o exercício dos direitos de cidadania, como os direitos políticos de comunicação e participação na esfera pública - a assim chamada liberdade dos Antigos.

Num outro âmbito, situa-se a autonomia privada, caracterizada pelo domínio das Leis, com os clássicos e básicos direitos garantidores das liberdades privadas dos membros da sociedade civil - sendo que, a esse respeito, os Direitos Humanos em sentido clássico podem ser identificados com o conceito de liberdade dos Modernos. Enfim, o ideal republicano como elemento de mediação, sob a égide do qual os sujeitos de direito só podem ser autônomos na medida em que, no exercício de seus direitos civis (privados), podem autocompreender-se como autores justamente daqueles direitos e obrigações que, como endereçados, são instados a obedecer.

O uso adequado e legítimo da autonomia pública depende da suficiente independência, assegurada como a garantia para o equânime exercício da autonomia privada. Paralelamente a isso, a regulação consensual da autonomia privada vincula-se ao uso adequado da autonomia política por parte de cidadãos livres e titulares de direitos civis. Como elemento de ligação entre esses dois planos, temos os direitos humanos, em sentido amplo, que se apresentam como condição de possibilidade para a realização jurídico-legal da prática de autodeterminação pelos cidadãos. É nesse sentido que ganha vulto a relação entre o conceito de direito e o processo legislativo, sobretudo em Estados Democráticos de Direito. Tão bem fundamentados sejam os direitos humanos, eles não podem ser, todavia, impingidos de fora por um poder soberano.

Descrever que a ideia de autonomia jurídica dos cidadãos exige que os destinatários da lei sejam capazes de entender-se a si próprios e, ao mesmo tempo, como autores da legislação a que se submetem. Seria contraditório com essa ideia que o legislador democrático tivesse a incumbência de descobrir direitos humanos, como se estes fossem fatos morais preexistentes, que só tivessem que ser incorporados à legislação positiva. 
Ao mesmo tempo, quando cidadãos ocupam a função de colegisladores, eles não são mais livres para escolher o médium no qual podem realizar sua autonomia. Eles participam do processo legislativo unicamente como sujeitos de direito; não está mais no poder deles decidir qual linguagem poderão empregar, nesse sentido, é possível apontar a fundamentação ética que deve interligar as relações sociais. A ideia democrática de autolegislação tem que adquirir sua validade unicamente no médium (gramática) do próprio direito positivo.

Tais análises remetem para a relação entre a teoria habermasiana do discurso um conceito procedimentalista de democracia, de acordo com a qual a classificação de papéis sociais especificamente atribuídos, em suas diferenças, concerne a níveis fundamentais de uma autocompreensão cultural da sociedade. É nesse nível que os cidadãos têm de esclarecer os aspectos que determinam quais diferenças entre as experiências e as situações de vida de grupos específicos de homens e mulheres são relevantes. A concepção procedimentalista do direito, com sua específica interpretação de processo democrático, tem de assegurar a autonomia privada e pública ao mesmo tempo: direitos individuais são entendidos no sentido de garantir autonomia para conduzir-se na esfera da vida privada; mas eles não podem ser adequadamente formulados a não ser que as pessoas concernidas primeiramente articulem e justifiquem, elas mesmas, num debate público, aqueles aspectos que são relevantes para o tratamento igual ou desigual em casos típicos. A autonomia privada de cidadãos igualmente habilitados só pode ser assegurada na medida em que eles, como cidadãos, exerçam sua autonomia cívica ou política.

\section{Ruptura da Tradição Normativa: a tensão entre facticidade e validade na esfera do direito}

Devidos às figuras predominantes da política e do mercado, o sistema econômico, destacado pelos liberais confronta-se com objetivos e ideologias traçados pelos sociais-democratas que buscam compensar a preponderância econômica com as intervenções do sistema político. A proposta fomentada pela escola do liberalismo aponta para uma com- 
petição de mercado livre e independente, como fator de regulação social, o que, por conseguinte, resulta em desigualdades materiais entre os indivíduos, assim como na monopolização e na duradoura crise da economia de mercado. No entanto, a proposta trazida pelos ideários do estado de bem-estar social, que buscam concretizar no mundo da vida - por meio do controle de mercado - a igualdade material fomentada pela intervenção do sistema político no mundo da vida, não obstante os desarranjos e transtornos burocráticos a serem resolvidos. O Estado liberal e o Estado de bem-estar confrontam-se reciprocamente, o que, de certa forma, prejudica, desestabilizando a manutenção da ordem social no seu todo e, por conseguinte, faz suscitar, no espírito da sociedade, uma descrença a uma possível estabilidade social. Devido à descrição da sociedade moderna, o médium do direito apresenta-se como um instrumento - especialmente na figura moderna do direito positivo - de colonização do mundo da vida, na medida em que as relações sociais cotidianas e familiares estão, a cada dia, mais impregnadas pela "juridificação" (DURÃO, 2008, p. 15).

As discussões em torno do conceito de direito, de sistema de direitos e de Estado Democrático de Direito permitiram inserir um elemento intermediário entre a solidariedade da ação comunicativa no mundo da vida e a instrumentalidade dos sistemas que operam estrategicamente. Destarte o direito, via sistema jurídico, representa o instrumento pelo qual opera o intercâmbio entre o mundo da vida e os sistemas, bem como entre ação comunicativa e estratégica. A partir do conceito do agir comunicativo - em que encontramos forças ilocucionárias da linguagem orientada ao entendimento - pode-se visualizar - no próprio conceito - sua função peculiar e necessária à coordenação da ação. A tensão entre facticidade e validade, que se introduz no próprio modo de coordenação da ação, coloca exigências elevadas para a manutenção de ordem social. Assim, torna-se indiscutível que tanto o mundo da vida como também as instituições que surgem naturalmente e o próprio direito têm que aniquilar as instabilidades de um tipo de socialização que se estrutura e se realiza com as tomadas de posição em termos de sim e de não, instauradas em face de pretensões de validade criticáveis (SILVA, 2013, p. 125).

Característica das sociedades modernas econômicas, esse problema geral se torna premente, sobretudo, pelo revestimento normativo das 
interações estratégicas não abarcadas pela eticidade tradicional. Desse modo, o direito passa ser visto como um instrumento que regula e integra o mundo social, bem como as relações que ocorrem nesse campo. Dado seu caráter transformador atuante no campo das reivindicações suscitadas no mundo da vida - comumente expressas em linguagens habituais do cotidiano segundo a racionalidade comunicativa e a racionalidade estratégica dos sistemas sociais - o direito oferece aos sujeitos duas vias que podem ser utilizadas a pretexto da finalidade das suas reivindicações. Por um lado, temos a figura da solidariedade da ação comunicativa atuante no mundo da vida; por outro, temos a figura da lei que, mediante seu poder coercitivo, regula as ações dos sujeitos que atuam na esfera do mundo social. Considerando a função social integradora que o direito exerce, ela não pode ser realizada tão somente pelo entendimento inerente ao mundo da vida, tampouco pelos sistemas funcionais reguladores, sobretudo o sistema econômico e político especializado na racionalidade estratégica. Habermas (2003a, p. 45) vê, na figura do direito positivo moderno, a possibilidade de assimilar - via ação comunicativa - a tensão entre facticidade e validade. À vista de tal possibilidade, Habermas buscar envolver-se com o problema central que abarca as possibilidades de reprodução social, à luz das pretensões de validade. A explicação poder-se-ia apresentar a partir do direito moderno, pois:

[...] uma vez que, segundo sua mediação, faz-se possível o surgimento de comunidades artificiais, comunidades jurídicas (sociedades mercantis, Estados federativos, comunidades internacionais, etc.), que, por sua vez, se compõem de membros livres e iguais, cuja sociabilidade resulta de uma pretensa ameaça de sanção e da suposição de um acordo racional a lhe dar fundamento. (MOREIRA, 1999, p. 113)

Precisamente, essa é a razão pela qual o conceito do agir comunicativo atribui às forças ilocucionárias da linguagem orientada ao entendimento a função importante da coordenação da ação. Os atos ilocucionários trazem, em seu bojo, por meio da força comunicativa do enunciado, a execução de uma ação; daí, conclui-se a vinculação entre agir comunicativo e a força dos atos ilocucionários da qual, a partir desse patamar, se 
poderá delinear uma nova relação entre facticidade e validade por meio do médium linguístico (MOREIRA, 1999, p. 114).

Não obstante a transição da razão prática para a ação comunicativa possa significar uma ruptura com a tradição normativa, a filosofia de Habermas não descarta as preocupações de ordem fundamental que tratam dos problemas que assolam o mundo da vida. Por um lado, temos a estrutura e o sentido de validade dos direitos subjetivos; por outro, temos as conotações idealistas de uma comunidade jurídica (ideal de fala) e, por tratar-se de uma associação constituída por cidadãos livres e iguais, essa comunidade determina, por si mesma, as regras de sua convivência. Ora, a sociedade moderna, dentre outras características que lhes são peculiares, traz destacado, em sua identidade, o multiculturalismo ideológico pluralista, o que suscita indagações quanto à possibilidade (ou não) de se coordenar, entre si, os planos de ações dos vários sujeitos, de tal modo que as ações de um partido (atores) possam estar atreladas (relacionadas) nas práticas do outro (SILVA, 2013, p. 126). Habermas considera que o possível entrelaçamento contínuo reduz o jogo das possibilidades de escolha, duplamente contingente, a uma medida que possibilita o entrelaçamento menos conflituoso possível de intenções e ações, portanto o surgimento de padrões de comportamento e da ordem social no geral.

A par disso, temos, ainda, a tarefa de esclarecer a questão de como a razão comunicativa faz a mediação com os fatos sociais e, mais ainda, em que sentido a razão comunicativa poderia incorporar-se aos fatos sociais? Fugindo ao risco de não confundir razão e realidade, Habermas (2003a, p. 36) procura demonstrar que a tensão entre facticidade e validade, inerente à linguagem, migra desta para o direito; enquanto a linguagem é utilizada apenas como médium para transmissão de informações e redundâncias, a coordenação ocorre por meio da influenciação recíproca de atores que agem uns sobre os outros de modo funcional. Portanto, tão logo, porém, as forças ilocucionárias das ações de fala assumem um papel coordenador da ação, a própria linguagem passa a ser explorada como fonte primária da integração social. É nisso que consiste o agir comunicativo.

A partir das proposições lógicas inseridas no contexto de fala, os sujeitos, na qualidade de falantes e ouvintes, tentam ajustar - a partir de 
um acordo de fala racional - interpretações comuns, formuladas com o foco no contexto da fala e com a finalidade de harmonizar entre si seus respectivos planos, via processo de entendimento, pelo caminho de uma busca incondicionada de fins ilocucionários. Sendo assim, no instante que os sujeitos de fala suspendem o enfoque objetivador de um observador e de um agente interessado imediatamente no próprio sucesso, e passam a incorporar um enfoque performativo de um falante que busca se entender como uma segunda pessoa sobre algo no mundo, as energias de ligação da linguagem podem ser impulsionadas (mobilizadas) para a coordenação de planos de ação. Assim, surge a vinculação entre agir comunicativo e a força dos atos ilocucionários e, a partir dessas premissas, será possível delinear uma nova relação entre facticidade e validade por meio do médium linguístico. Vejamos que, com a colocação do problema da idealização inevitável realizada pela linguagem, idealização que se dá com o entendimento mútuo, surge o perigo de confundir razão e realidade. Pelo fato da razão comunicativa estar adscrita às realidades sociais, devemos responder à questão de como se dará a mediação entre razão comunicativa e fatos sociais ou, em que sentido, a razão comunicativa poderia incorporar-se aos fatos sociais (HABERMAS, 2003b, p. 27). Ao que parece, a intenção de Habermas é demonstrar como a tensão entre facticidade e validade, inerente à linguagem, migrará desta para o direito:

A partir do momento em que as ideias sobre a oposição abstrata entre o inteligível e o fenomenal, que serviam de pano de fundo à metafísica kantiana, não convenciam mais ninguém e, a partir do momento em que o entrelaçamento especulativo e dialético entre as esferas da essência e da aparência, criado por Hegel, perdeu sua plausibilidade, entraram em cena, no decorrer do século XIX, interpretações empiristas que passaram a dar preferência a uma explicação psicológica das relações lógicas ou conceituais: contextos de validade foram assimilados a processos fáticos de consciência. (HABERMAS, 2003a p. 27)

Para o teórico alemão, esse movimento encontra-se resumido na tese de Frege, ao se procurar diferenciar pensamento e representação (FREGE apud HABERMAS, 2003a, p. 29-31). A crítica à opinião, segun- 
do a qual o pensamento não é mais do que consciência representadora, repousa nessa consideração simples. Nas representações, o que se tem tão somente são os objetos, sendo que, por outro lado, estado de coisas ou de fatos é apreendido em pensamentos. Logo, isso significa dizer que pensamentos e fatos devem ser mediados no mundo dos objetos representáveis, de modo a tornar-se possível o aprendizado; eles só são acessíveis (pensamentos e fatos) quando representados em estados de coisas expressos por meio de proposições.

Os pensamentos - dado o fato de ultrapassarem os limites de uma consciência individual - articulam-se por meio de proposições assertivas, torna-se, então, possível ler a estrutura dos pensamentos, observando a estrutura das proposições, e as proposições são consideradas por Habermas como partes elementares de uma linguagem gramatical, passíveis de verdade. Sendo certo que os pensamentos são expressos por meio das proposições, precisa-se do médium linguístico para que se manifeste, compreensivelmente, a distinção entre pensamentos e representações. Nisso, consiste a tese habermasiana de que as expressões linguísticas tenham significado idêntico para os mais diversos usuários (SILVA, 2003, p. 71).

Na prática, Habermas considera que, necessariamente, os membros de determinada comunidade de linguagem devem considerar que falantes e ouvintes podem compreender uma expressão gramatical de modo idêntico, para tanto, devem julgar que as mesmas expressões conservam igual significado independente da variedade de situações e dos atos de fala nos quais são empregadas. A partir desse raciocino lógico gramatical, são concebidas regras que emprestam formas determinadas a eventos linguísticos, numa relação fonética, sintática e semântica, reconhecíveis e solidificadas por meio das variações. No tocante a isso, consiste a relação entre o geral e o particular, ou, seguindo a tradição, entre essência e aparência. Sendo assim, a idealidade pressuposta no pensamento aponta a generalidade que se faz transcender à consciência individual, ao que, por conseguinte, não obstante a variedade de vozes abertas e acessíveis existentes no mundo de fala preserva-se um elo condutor opondo-se ao acesso das representações de uma consciência individual, particular solipsista. Logo, para determinar a validade de um pensamento expresso em enunciado, via de regra, o juízo de validade exige, ademais o conteúdo 
assertivo, uma determinação ulterior que subjaz à pergunta deque se ele é verdadeiro ou falso. Dessa forma, sujeitos falantes e pensantes podem se posicionar diante de qualquer pensamento, dizendo sim ou não; dado o fato da existência do pensamento, acrescenta-se a isso, um ato de apreciação crítica (HABERMAS, 2003a, p. 29). Com isso, descreve Habermas que somente o pensamento traduzido em proposições ou a proposição verdadeira expressam um fato.

\section{A Função Instrumental do Agir Comunicativo: integração, manutenção e ordem social}

Do exame aplicado que se propôs até aqui com relação ao significado e ao conceito daquilo que se entende por expressões linguísticas e por validade de preposições assertóricas, percebe-se que, para Habermas dado esse estudo, toca-se em idealizações que seguem conectadas ao médium da linguagem. Ademais o conceito, bem como seu significado, a idealidade que dele se extrai, sua generalidade, são acessíveis mediante uma análise pragmática da linguagem utilizada para o entendimento mútuo. As idealizações conectadas na linguagem podem assumir um significado relevante para a teoria da ação, o que se poderia constatar na hipótese em que as forças de ligação ilocucionárias de atos de fala sejam utilizadas com a finalidade de coordenação de planos de ação de diferentes atores (HABERMAS, 2003b p. 35). O conceito habermasiano do agir comunicativo faz com que as suposições contrafactuais dos atores, que orientam seu agir por pretensões de validade, adquiram relevância imediata para a construção e a manutenção das ordens sociais. Com isso, Habermas pretende demonstrar como a tensão entre facticidade e validade - inerente à linguagem - está pragmaticamente interligada (simbiose) com a integração de indivíduos socializados comunicativamente. Do entendimento linguístico sucede a manutenção das ordens sociais subjacente ao reconhecimento de pretensões de validade normativa que, advém da ligação dos atos ilocucionários de fala reconhecidos mutuamente.

Ao postulado da concretizada ordem social, corolário do entendimento mútuo, liga-se a integração social, predicado este compreendido como a solução do seguinte problema: como é possível coordenar entre si 
os planos de ação de vários atores, de tal modo que as ações de um partido possam ser "engatadas" nas do outro? A integração social é, assim, descrita pelo "engate" das múltiplas perspectivas de ação, de modo que tais perspectivas possam ser resumidas em ações comuns, ou seja, restringem-se às possibilidades de escolha e, consequentemente, aos possíveis conflitos. No ato de integração social, as diversas perspectivas de comportamento são direcionadas para um fim comum que possibilita, concomitantemente, tanto a realização de uma determinada ação como também sua mobilização para um status do qual venha a ser gerada uma adesão. Porém, tão logo as forças ilocucionárias das ações de fala assumem um papel regulador na ação, a própria linguagem passa a ser explorada como fonte primária da integração social; aliás, nisso consiste o agir comunicativo. Nessa perspectiva, consoante a função reguladora proporcionada pela força ilocucionária da ação de fala, temos a conexão entre as diversas alternativas de condutas fomentadas. Destarte, são criados padrões de comportamento, de modo a tornar menos conflituosas as interações entre os sujeitos. É exatamente o redirecionamento das diversas alternativas de ação que possibilita o surgimento de uma ordem social, uma vez que esse redirecionamento reduz as alternativas a uma medida comum que passa a reduzir o risco do dissenso.

Ademais, os atores, na qualidade de falantes e ouvintes, empenham-se em negociar interpretações comuns da situação e estabelecer entre si concordâncias com relação aos seus respectivos planos, por meio de processos de entendimento e pelo caminho de uma busca incondicionada de fins ilocucionários. Os planos de ação ficam, então, condicionados a um posicionamento a ser tomado pelos participantes, que consiste no ato de suspender o enfoque objetivador de um observador, bem como de um agente interessado, imediatamente, no próprio sucesso e, doravante, passam a adotar um enfoque performativo que corresponda ao de um falante que deseja entender-se como uma segunda pessoa sobre algo no mundo (HABERMAS, 2003a p. 36).

A partir dessa instrumentalidade, o sujeito pode recorrer, adequadamente, a algumas pretensões de validade com relação à sua fala, na qual se dá o processo de formação do seu "eu", ou seja, dada a possibilidade real de atuação incutida no agir comunicativo, gradativamente, o sujeito 
da fala obterá autonomia e atuação interativa com os demais sujeitos, em que o agir comunicativo está inserido; participantes unem-se em torno da pretensa validade de suas ações de fala, ou constatam dissensos, os quais eles, de comum acordo, levarão em conta no decorrer da ação comunicativa. Do agir comunicativo, extrai-se uma conotação de que, mediante o uso da linguagem, os sujeitos findarão seus atos (pretensões de validade criticáveis) de fala no instante em que se fixar o entendimento formulado por eles. Isso significa dizer que o entendimento passa a ser interpretado como um sistema ou processo de convencimento objetivado (racionalmente) intersubjetivamente pelos sujeitos, que coordena as atuações de todos os integrantes por meio da razão, de forma que, as ações de fala são entendidas como instrumentos para atingi-lo; nesse sentido, o entendimento é o processo de obtenção de um acordo entre sujeitos linguística e interativamente competentes (HABERMAS, 1987, p. 432). Avalia o filósofo que, em qualquer ação de fala, são levantadas pretensões criticáveis, que apontam para o reconhecimento intersubjetivo. Em sua leitura, Luiz Moreira (1999, p. 123) levanta uma ressalva quanto à situação em que essa estrutura básica não se mostra suficiente para garantir a integração social, ao que, por conseguinte, surgirá a possibilidade do dissenso ou a respectiva necessidade de legitimar racionalmente nossas pretensões. Daí, quando a pergunta crítica pelo porquê de tal conduta se instala, é necessário que a busca dos fins ilocucionários de nossas ações de fala passe a coordená-las.

Dada a distinção apresentada entre a idealidade da generalidade dos conceitos e dos significados e a idealidade dos conceitos de validade, verifica-se que tais distinções podem ser entendidas, por um lado, com o auxílio da estrutura de regras da linguagem em geral e, por outro lado, lançando mão dos pressupostos do uso da linguagem orientados pelo entendimento. Para Habermas (2003b p. 37-38), ambos os níveis de idealização estão atreladas na própria comunicação linguística e, desse modo, passam a intervir na constituição da realidade social de interações interligadas que se propagam no espaço e no tempo, seguindo o caminho do agir comunicativo. A idealidade da generalidade do significado delimita, demarcando os contextos do agir comunicativo, na medida em que os participantes não conseguem articular formalmente o propósito de entende- 
rem-se sobre algo no mundo, nem atribuir às expressões utilizadas significados idênticos, caso não seja possível aos sujeitos de fala apoiarem-se numa linguagem comum. Destarte, os mal-entendidos só poderão ser descobertos como tais quando esta condição for preenchida.

Compreende-se, assim, que a sociologia pode sim atribuir aos próprios sujeitos, que agem comunicativamente capacidades suficientes para superarem os estorvos de comunicação oriundos de simples mal-entendido, desde que, para tanto, a sociologia, desejosa de ter acesso ao seu campo de objetos, considere a tensão entre facticidade e validade, bem como os participantes da interação, atribua cada qual, reciprocamente, a tomada de consciência de seus atos, ou seja, devem presumir ser capazes de orientar seu agir por pretensões de validade. Entretanto, a partir do momento em que essa expectativa de racionalidade se revela falsa, os participantes - bem como os observadores sociológicos como virtuais participantes - passam do enfoque performativo para o enfoque objetivador (HABERMAS, 2003a, p. 38).

Nesses fatos sociais encontram-se tensões que abarcam certo conteúdo ideal, pois reagem a pretensões de validade, as quais, para serem justificadas, pressupõem, necessariamente, o assentimento de um auditório idealmente ampliado. Com isso, tanto as normas como os enunciados - a validade que se quer seja reconhecida para ambas - transcendem, de acordo com seu sentido, espaços e tempos; de tal modo que, a pretensão atual é levantada sempre aqui e agora no interior de determinados contextos podendo ser aceita ou rejeitada ao que, por conseguinte, trará consequências para ação, gerando fato. Destarte, a validade pretendida por nossos proferimentos e pelas práticas de nossa justificativa distingue-se da validade social dos 'standards' exercitados factualmente, das expectativas estabilizadas por meio da ameaça de sanções ou do simples costume.

O caráter de incondicionalidade impresso nas pretensões de validade está enraizado nos processos de entendimento factuais. Como pretensões, elas não se limitam a tempo ou espaço, transcendem qualquer contexto. Entretanto, devem ser colocadas e aceitas aqui e agora, caso contrário - considera Habermas - não poderão ser portadoras de um acordo capaz de coordenar a ação, pois não existe, para isso, um contexto zero. 


\section{Mundo da Vida e a Construção das Identidades: normatiza- ção e valoração para integração social}

Qualquer ato de fala, por meio do qual um falante se entende com outro sujeito sobre algo no mundo, circunscreve a expressão linguística em três referências com o mundo: em referência com um falante, com o ouvinte e com o mundo. Sob a perspectiva das formações de interações, nós nos ocupamos - segundo Habermas (1990a, p. 95) - principalmente do segundo aspecto, configurando assim as relações interpessoais. Concomitante às implementações das relações interpessoais, os participantes da interação assumem ações coordenadas a que subjazem atos de fala. Entretanto, há uma ressalva quando estamos diante de uma situação preenchida por uma única função da linguagem, dado que, desse modo, o insucesso dos atos de fala será inevitável. Os atos de fala, como já analisados em linhas anteriores, servem, em geral, à coordenação, ao que possibilitam aos atores o consenso ou acordo racionalmente motivado; e, nisso, há a contribuição das outras duas funções da linguagem, a saber: a representação e a expressão. Portanto, diferente do referencial tomado pelo ator, o ponto de vista da coordenação dos atos de fala encontra-se num nível abstrato, não se confundindo com o do primeiro, dado o fato que o referencial utilizado pelo ator visa a produzir diretamente uma determinada relação interpessoal. A integração social passa ser estabelecida mediante a coordenação da ação, que toma o mundo da vida compartilhado intersubjetivamente pelos seus participantes.

Como falante e ouvinte se entendem frontalmente acerca de algo no mundo, as ações de ambos se desenvolvem dentro do horizonte do seu mundo da vida em comum e este continua a ser, para os intervenientes, como um pano de fundo intuitivamente conhecido, não problemático, não desmembrável e holístico. Nesse sentido, o mundo da vida forma um horizonte e, ao mesmo tempo, oferece para os sujeitos da fala um conjunto de evidências culturais das quais os participantes, no ato de comunicar e nas suas interpretações, extraem padrões de interpretações consentidos. A situação do discurso é, no que respeita à temática respectiva, o excerto de um mundo da vida que tanto constitui o contexto como fornece as condições para o processo de compreensão (HABERMAS, 1990b p. 278-279). 
A aclarada descrição aponta aos sujeitos uma nova perspectiva que permite inquirir acerca da contribuição das ações comunicativas à reprodução de um mundo da vida. Nesse sentido, o mundo da vida, visto como o horizonte de convicções comuns e indubitáveis, suscita novos conhecimentos familiares em consequências dos discursos que são proferidos nas arenas onde os atos de fala ocorrem. O mundo da vida é, em outras palavras, um bloco de modelos consentidos de interpretação, de lealdade e práticas (HABERMAS, 1990a, p. 86).

Para Habermas, a posição fenomenológica husserliana espelha-se na filosofia da consciência da qual se entende que o eu solipsista é responsável pelo conhecimento do conteúdo do mundo da vida, seja ele um objeto, ou outros indivíduos, ou até mesmo o reconhecimento do próprio eu como parte do mundo já conhecido. Tal concepção é afastada por Habermas, que toma a filosofia da linguagem como instrumento pelo qual se explicitam o conhecimento e o entendimento dos indivíduos construídos intersubjetivamente (PIZZI, 2006, p. 132). Logo, ao executar um plano de ação, o ator domina uma situação que faz parte do mundo contextualizado e interpretado por ele. Tal assertiva leva ao segundo ponto de discordância entre Habermas e Husserl. Habermas afirma que Husserl utiliza o conceito de mundo da vida como oposto às idealizações (do medir, da suposição da causalidade e da materialização) feitas nas ciências naturais, Husserl (apud HABERMAS, 1990a, p. 88- 89) vê o mundo da vida como a esfera imediatamente presente de realizações originárias.

Na filosofia habermasiana, o mundo da vida ocupa posição central na coordenação e estabilização da ação social, constituindo o pano de fundo do agir comunicativo, um horizonte para situações de fala e uma fonte de interpretações para os atores que agem comunicativamente. Sua função primordial é estabilizar essa comunicação improvável e, ao mesmo tempo em que possibilita o consenso, está aberta à constante problematização e ao grande risco do dissenso (falibilismo). O conceito de mundo da vida na filosofia habermasiana abarca uma junção de três elementos - cultura, sociedade e personalidade e, acoplada a eles, a linguagem, que cumpre sua função fundamental na reprodução do mundo da vida. Sob o aspecto funcional do entendimento, a ação comunicativa serve à tradição e à renovação do saber cultural; sob o aspecto de coordenação da 
ação, serve à integração social e a criação da solidariedade; e sob o aspecto da socialização, finalmente, serve à formação de identidades pessoais (HABERMAS, 1987, p. 196). Nesse sentido, a racionalização do mundo da vida refere-se à diferenciação desses três aspectos estruturantes. Por meio da ação comunicativa, os participantes da integração linguística fazem um resgate desses elementos, a partir de pretensões de validade (discursos e argumentos racionalmente justificáveis) criticáveis (passíveis de problematizações) que levarão a um entendimento ou mesmo a um acordo (consenso).

Sob o aspecto do entendimento, as ações de fala servem para a tradição e a continuidade do saber cultural; por outro lado, sob o aspecto da socialização, as ações de fala servem à formação e à conservação de identidades pessoais. Isso aponta a função integradora das ações de fala que replanta a ordem social do mundo da vida:

Podemos imaginar os componentes do mundo da vida, a saber, os modelos culturais, as ordens legitimas e as estruturas de personalidade, como se fossem condensações e sedimentações dos processos de entendimento, da coordenação da ação e da socialização, os quais passam por meio do agir comunicativo. Aquilo que brota das fontes do pano de fundo do mundo da vida e desemboca no agir comunicativo, que corre por meio das comportas da tematização e que torna possível o domínio de situações, constitui o estoque de um saber comprovado na prática comunicativa. (HABERMAS, 1990a, p. 96)

As interpretações a que chegamos a respeito de algo no mundo promovem, aos atores das ações de fala, um saber consolidado sob sua égide os quais são transmitidos na rede de interação de grupos sociais. Esses saberes assumem (são convertidos em) valores e normas pelos trilhos dos processos de socialização, ao que, por conseguinte, são condensados na forma de enfoque, competências, modos de percepção e identidades. O substrato do mundo da vida, isto é, seus componentes resultam da extensão contínua do saber válido, bem como da estabilização de solidariedades grupais e da formação de atores responsáveis, mantendo-se, todavia, por meio deles. Dessa forma, as interações fomentadas pela prática comunicativa cotidiana estendem-se sobre o campo semântico dos conte- 
údos simbólicos presentes no mundo da vida, atingindo todas as dimensões que integram o espaço social, bem como no quesito temporal, alcançam o tempo histórico. A cultura, da mesma forma que a sociedade e as estruturas de personalidade, é formada a partir de ações de fala que promovem o entendimento sobre algo no mundo:

[...] cultura é o armazém do saber, do qual os participantes da comunicação extraem interpretações no momento em que se entendem mutuamente sobre algo. A sociedade compõem-se de ordens legítimas por meio das quais os participantes da comunicação regulam sua pertença a grupos sociais e garantem solidariedade. Conto entre as estruturas da personalidade todos os motivos e habilidades que colocam um sujeito em condições de falar e de agir, bem como de garantir sua identidade própria. Para os que agem comunicativamente, a cultura forma o cone luminoso no interior do qual surgem entidades que podem ser representadas ou manipuladas; ao passo que as normas e vivências se lhes afiguram como algo no mundo social ou num mundo subjetivo, ao qual eles podem referir-se assumindo um enfoque expressivo ou conforme as normas. (HABERMAS, 1990a, p. 96)

A integração social, fenômeno que se articula sobre a tensão existente entre o factual e o contrafactual, nos direciona para a implementação do conceito mundo da vida. Não obstante a ocorrência do dissenso oriundo da tensão entre o factual e o contrafactual, a coordenação das ações se apresenta de tal modo que se torna possível, mesmo estando às ameaças constantes, estabelecer uma ordem social. Normalmente, as divergências ocorrem devido às circunstâncias que criam rupturas com o entendimento, acarretando uma ameaça para a coordenação da ação. Portanto, Habermas (2003b, p. 40) analisa o primeiro passo reconstrutivo das condições da integração social a ser tomado pelos atores de fala os levará ao conceito mundo da vida. O passo a ser tomado parte de um referencial consectário de um problema: como é possível surgir ordem social a partir de processos de formação de consenso que se encontram ameaçados por uma tensão explosiva entre facticidade e validade? Em se tratando do agir comunicativo, a dupla contingência que pode ser absorvida por qualquer modo de interação assume forma precária que pode ceder ao inevitável 
risco de dissenso sempre presente, embutido no próprio mecanismo de entendimento, de maneira que esse risco acarreta uma instabilidade gravosa para a coordenação da ação.

Considerando o fato de existirem poucas alternativas à disposição, estas devem ser interpretadas como simples concertos à desconsideração de pretensões controversas. As vias alternativas tomadas pelos sujeitos nas ações de fala atenuam o campo das convicções compartilhadas e, por conseguinte, tornam diminutos os discursos mais pretensiosos, ou seja, as poucas alternativas postas à disposição encolhem as possibilidades da passagem dos simples concertos para os discursos mais pretensiosos, cujo término é imprevisível e cujos efeitos de problematização são perturbadores. Destarte, chega-se ao inevitável dissenso entre os agentes, ocasionando uma mudança no agir comunicativo - com fito ao entendimento redirecionando-o à implementação de um agir estratégico, orientado para o sucesso de cada um. Assim, os entendimentos explícitos comumente formulados com origem em si mesmo se dão no horizonte das convicções comuns não problemáticas (problematizadas), e ao mesmo tempo, eles se alimentam das fontes daquilo que sempre lhes pareceu habitual ou comum. O mundo da vida passa a ser entendido como fonte precípua instituidora das ações de fala, assim como, também, passa a ser entendido como pano de fundo interpretativo o qual se reproduz a partir de ações comunicativas, ou seja, o mundo da vida forma o horizonte para as situações de fala e para as interpretações daquilo que é reproduzido por meio das ações comunicativas (HABERMAS, 2003b, p. 40).

A par desse envolvimento do qual somos acometidos por parte do mundo da vida que nos oferece uma certeza imediata compreendida por nós como fonte para nossas ações de fala, essa fonte - condensada e deficiente de poder - oferece-nos um saber que se apresenta de modo irreflexo. Não obstante essas fragilidades, guiamo-nos como se esse saber fosse um saber condensado que possui características de uma saber absoluto. Ora, essa fonte de saber ordinária, por nos parecer habitual e familiar, assume um caráter genuinamente original, no qual, comumente, nos remetemos a ela como se fosse algo inquestionável, uma vez que "não" nos parece falível e, tampouco, falsificável. Entretanto, esse saber perde essa dimensão de absoluto e inatacável quando passa ser arrostado e confron- 
tado com as pretensões de validade estantes na tensão entre facticidade e validade (factual e contrafactual). Isso significa dizer que, no instante em que ele é chamado como fonte para fundamentar uma base interpretativa, nesse exato momento, sua inquestionabilidade decompõem-se como fonte de mundo da vida. Desse ponto de vista, suscita uma peculiar questão: o que empresta ao saber que serve de pano de fundo uma certeza absoluta e lhe confere, subjetivamente, a qualidade de um saber condensado? Para Habermas, a resposta a ser dada seria objetiva, ou seja, o que confere subjetivamente a qualidade de um saber condensado seria tão somente a qualidade que falta ao saber objetivo (SILVA, 2003, p. 72). Isso significa dizer que nós, quando utilizamos desse tipo de saber, o fazemos, sem ter a consciência de que ele pode ser falso, isto é, ele não representa um saber em sentido estrito, pois não é falível nem falsificável. Falta-lhe o nexo interno com a possibilidade de vir a ser problematizado, pois ele só entra em contato com pretensões de validade criticáveis no instante em que é proferido e, nesse momento da tematização, ele se decompõe como pano de fundo do mundo da vida (HABERMAS, 2003b, p. 41).

\section{A Função do Direito no Mundo da Vida}

$\mathrm{Na}$ teoria do agir comunicativo, após o resgate crítico do conceito do mundo e sistema da vida, bem como no ajuste da relação entre ambos, Habermas analisa o papel do direito numa sociedade que possibilita dois modos de agir utilizados pelos sujeitos, a saber: o comunicativo e o estratégico.

Ao descrever o papel da "juridicização" - processo construído no decorrer da história - Habermas aponta duas funções do direito: 1) direito como instituição e 2) direito como meio de controle. $\mathrm{O}$ direito como instituição pertenceria às ordens legítimas da ordem do mundo da vida e, como tal, sua legitimidade reclama mais do que uma simples legalidade formal, ou seja, uma justificação material. Nessa perspectiva, a legitimidade material estaria preenchida desde que fosse observada - vida de regra - a concordância das normas jurídicas com as normas morais. No caso do direito como meio de controle, teríamos a identidade do direito 
configurada a partir da sua instrumentalidade de regulação dos subsistemas compostos pelo Estado e pela Economia; assim, o direito funcionaria como uma forma de constituir as relações jurídicas observadas nesses sistemas, e a sua legitimidade estaria condicionada tão somente à sua própria positivação, o que implicaria sua legalidade formal. Quando se emprega como meio de controle, o direito fica descarregado da problemática da fundamentação e só por meio da correição dos procedimentos permanece conectado com o corpus iuris exigido na legitimação material.

As instituições jurídicas pertencem aos componentes sociais do mundo da vida. E como o resto das normas de ação que não vêm respaldadas pela sanção do Estado, podem ser moralizadas, ou seja, abordadas na sua dimensão constitutiva ética, quando se apresenta alguma dissonância especial. (HABERMAS, 1987, p. 517)

Quando o direito, como meio, amplia seu domínio, possibilitando a introdução dos sistemas capitalistas e do poder na reprodução simbólica do mundo da vida, ocorre o que Habermas define como colonização interna do mundo da vida. O emprego da expressão colonização se deve ao fato de que questões antes abertas a uma proposta de solução comunicativa a ser travada no mundo da vida são transportadas para uma discussão jurídica que, além de abafar tal produção genuína de soluções pelos próprios afetados, reflete a estrutura do direito não referida ao próprio mundo da vida, mas sim aos sistemas da Economia e do Estado (CHAMON, 2005, p. 184).

Na segunda fase de seu pensamento, Habermas (2003a, p. 13) dá continuidade à ideia de que a sociedade moderna é marcada por uma racionalidade comunicativa arrostada aos elementos do mundo da vida. Não obstante, quanto ao direito, entende o filósofo "[...] numa época de política inteiramente secularizada, não se pode ter nem manter um Estado de direito sem democracia radical". Nesse sentido, há um distanciamento da ideia de um direito que se legitima a partir de concepções ideológicas; o posicionamento ora apresentado se vincula à ideia do direito que se legitima a partir do nexo interno entre a soberania popular e os direitos humanos. Esses sujeitos, como participantes de uma comunidade jurídi- 
ca devem compreender-se como indivíduos em si mesmo emancipados, bem como responsáveis pela auto-organização democrática que forma o núcleo normativo desse projeto. Numa retomada da teoria do agir comunicativo, Habermas passa a considerar seriamente as possibilidades do dissenso numa prática comunicativa. Tal risco se mostra muito evidente, analisando o fato da complexidade que envolve a sociedade moderna multicultural, em que as interações estratégicas são costumeiramente utilizadas pelos sujeitos. Portanto com a introdução do agir comunicativo em contextos do mundo da vida e a regulação do comportamento por meio de instituições originárias podemos explicar como é possível a integração social em grupos pequenos e relativamente indiferenciados, na base improvável de processos de entendimento em geral. É certo que os espaços para o risco do dissenso embutido em tomadas de posição em termos de sim/não em relação às pretensões de validade criticáveis crescem no decorrer da evolução social (SILVA, 2003, p. 79). Assim, quanto maior for a complexidade da sociedade e mais se ampliar a perspectiva restringida etnocentricamente, maior será a pluralização de formas de vida, as quais inibem as zonas de sobreposição ou de convergência de convicções presentes na esfera do mundo da vida.

Este esboço é suficiente para levantar o problema típico das sociedades modernas: como estabilizar, na perspectiva própria dos atores, a validade duma ordem social, na qual ações comunicativas tornam-se autônomas e claramente distintas de interações estratégicas? (HABERMAS, 2003b, p. 44-45)

O direito passa, então, a ser visto como resposta adequada ao presente questionamento. Ao perceber que a linguagem, mesmo quando utilizada comunicativamente, não tem força suficiente para assegurar a integração social, devido ao multiculturalismo e às complexidades ideológicas que envolvem a sociedade moderna, torna praticamente impossível estabelecer uma base comum para regularização das questões problematizadas. Habermas (2003b, p. 110) aponta o direito como meio adequado para preencher esse déficit estabilizador social. Isso porque o direito moderno positivado se apresenta com a pretensão à fundamentação sistemática, à interpretação obrigatória e à imposição - que institucionaliza (atribui validade) as pretensões de verdade (assertivas) que surgem 
na esfera pública -, com sua força impositiva que alcança todos, indistintamente, que estejam submetidos a sua ordem legal. Entretanto o direito não é impositivo por uma questão de ordem formal, ou seja, não é um direito imposto por quem detém o poder. O direito legítimo se configura a partir do seu desempenho como médium linguístico entre os diferentes âmbitos de ação, de forma que sua normatividade resulte não somente da sanção do Estado, mas também da observância concretizada por parte dos atores sociais. A legitimidade do direito não mais advém de sua submissão a uma moral superior, mas pelo fato de que os afetados pelas normas jurídicas se reconhecem como coautores dessas normas positivadas: o direito não consegue seu sentido normativo pleno per se por meio da sua forma, ou por meio de um conteúdo moral dado a priori, mas por meio de um procedimento que instaura o direito, gerando legitimidade (SILVA, 2014, p. 248).

A positivação política autônoma do direito, garantida a partir de um direito legitimamente instituído, concretiza-se em direitos fundamentais dos quais (surgem), asseguram condições para iguais pretensões à participação em processos legislativos democráticos, que demandam o exercício do poder político devidamente (legalmente) instituído. Além disso, o Estado, no seu exercício burocrático de dominação legal, faz valer concretamente a formação da vontade política que se organiza na forma do legislativo e, para tanto, conta diretamente com o poder executivo em condições de realizar e implementar os programas acordados. A presença do Estado no seu caráter de jurisdição - tanto administrativa como judicial - dependem da medida em que a sociedade se vale do médium do direito para influir conscientemente em seus processos de reprodução. Com isso, fala-se na dinâmica da autoinfluência, acelerada por meio dos direitos de participação que fundamentam pretensões ao preenchimento dos pressupostos sociais, culturais e ecológicos úteis para o aproveitamento simétrico de direitos particulares de liberdade e de participação na vida política (SILVA, 2013, p. 224). Em síntese, o Estado é necessário como poder de organização, de sanção e de execução, porque os direitos têm que ser implantados, porque a comunidade de direitos necessita de uma jurisdição organizada e de uma força para estabilizar as identidades. 
Tais aspectos não constituem meros complementos, funcionalmente necessários para o sistema de direitos, e sim, implicações jurídicas objetivas, contidas in nuce nos direitos subjetivos (HABERMAS, 2003b, p. 171). O poder organizado politicamente não se aproxima do direito como algo que lhe seja externo, pelo contrário, é pressuposto pelo direito; em outras palavras, o poder político organizado se estabelece em formas do direito. Nesse sentido, o poder político só pode desenvolver-se mediante a constituição de um código jurídico institucionalizado em conformidade com os direitos fundamentais. No Estado de direito, as decisões coletivamente obrigatórias são implantadas mediante o poder político organizado que o direito precisa tomar para a realização das suas funções próprias; não se revestem apenas a forma do direito, essas decisões devem - também - ser legitimadas pelo direito corretamente estatuído. As formações discursivas da opinião e da vontade figuram como premissas fundamentais para legitimidade do direito, ou seja, dentro do pensamento pós-tradicional, só vale como legítimo o direito que fora elaborado no interior de uma comunidade democrática que, utilizando do discurso racional, convenciona, normas reconhecidas reciprocamente pelos sujeitos. Consequentemente, institui-se a incorporação do exercício da autonomia política dos cidadãos em toda esfera do Estado - a legislação é reconhecida como um poder no Estado (SILVA, 2013, p. 81). A transação dos direitos reciprocamente atribuídos na via da socialização horizontal pelos civis para formas verticais de organização socializadora faz com que a prática de autodeterminação dos civis seja institucionalizada - como formação informal da opinião na esfera pública política, como participação política no interior e no exterior dos partidos, como participação em votações gerais, na consulta e tomada de decisão de corporações parlamentares, etc. (HABERMAS, 2003b, p. 17-173). Com efeito, a soberania popular interliga-se internamente com as liberdades subjetivas dos civis, essa soberania, por seu turno, entrelaça-se com o poder politicamente organizado, de modo que o princípio "todo o poder político emana do povo", paulatinamente, concretiza-se por meio de procedimentos e pressupostos comunicativos de uma formação institucionalmente diferenciada da opinião e da vontade. 
Com relação ao direito, sua contribuição para a função intrínseca do poder administrativo (realizar fins coletivos) evidencia-se, especialmente, no desenvolvimento de normas secundárias, que, segundo Schumacher (2000), não se tratam tão somente daquelas normas que conferem poder (e até criam) às instituições governamentais dotando-as de jurisdições especiais, como também normas organizacionais que estabelecem procedimentos para a existência e a gestão administrativa ou judicial de programas jurídicos. Desse modo, a atividade do direito, sua função e sua aplicabilidade atingem outras esferas que não somente a da atividade jurisprudência jurídica, mas alcança também a esfera das instituições de governo - procedimentos e competências - garantindo, assim, a autonomia privada e pública dos cidadãos (SCHUMACHER, 2000, p. 245).

\section{Conclusão}

O conceito habermasiano do agir comunicativo, que estabelece o entendimento linguístico como premissa fundamental para o mecanismo de coordenação da ação, faz com que as suposições contrafactuais dos atores, que orientam seu agir por pretensões de validade, adquiram relevância imediata para a construção e a manutenção das ordens sociais. Com isso, Habermas pretende demonstrar como a tensão entre facticidade e validade - inerente à linguagem - está pragmaticamente interligada (simbiose) com a integração de indivíduos socializados comunicativamente. Do entendimento linguístico sucede a manutenção das ordens sociais subjacente ao reconhecimento de pretensões de validade normativa que, advém da ligação dos atos ilocucionários de fala reconhecidos mutuamente. Nossas ações de fala situam-se em um mundo da vida compartilhado intersubjetivamente que, mediado por um pano de fundo consensual, nos possibilita um entendimento prévio sobre algo. Avalia Habermas que, em qualquer ação de fala, são levantadas pretensões criticáveis, que apontam para o reconhecimento intersubjetivo.

$\mathrm{Na}$ filosofia habermasiana, o mundo da vida ocupa posição central na coordenação e estabilização da ação social, constituindo o pano de fundo do agir comunicativo, um horizonte para situações de fala e uma fonte 
de interpretações para os atores que agem comunicativamente. Entretanto o direito não é impositivo por uma questão de ordem formal, ou seja, não é um direito imposto por quem detém o poder. O direito legítimo se configura a partir do seu desempenho como médium linguístico entre os diferentes âmbitos de ação, de forma que sua normatividade resulte não somente da sanção do Estado, mas também da observância concretizada por parte dos atores sociais. A legitimidade do direito não mais advém de sua submissão a uma moral superior, mas pelo fato de que os afetados pelas normas jurídicas se reconhecem como coautores dessas normas positivadas: o direito não consegue seu sentido normativo pleno per se por meio da sua forma, ou por meio de um conteúdo moral dado a priori, mas por meio de um procedimento que instaura o direito, gerando legitimidade.

No Estado de direito delineado por regras da teoria do discurso a soberania popular instala-se nos círculos de comunicação de foros e corporações destituídos de sujeitos determinados. Portanto, dado o anonimato, seu poder comunicativo diluído pode entrelaçar ao poder administrativo do aparelho estatal à vontade dos cidadãos. Nesse sentido, no Estado de direito democrático, o poder político diferencia-se em poder comunicativo e administrativo. Dada a correlação interna entre política e direito, a tensão entre facticidade e validade, no Estado Democrático de Direito, estende-se ao âmbito do próprio poder político. A política com seu domínio, por um lado, vale-se da potencial ameaça fundada pela força da "caserna" e, por conseguinte, deve estar autorizada do ponto de vista do direito legítimo; a dominação política deve espelhar a imagem do poder legitimado e organizado do ponto de vista jurídico, ou seja, o exercício do poder na forma do direito não deve ser deslocado do momento de sua fundamentação.

Essa preocupação consiste exatamente em reconstruir a constituição cooriginária entre poder político e o direito, mostrando que, mediante essa relação, resulta um novo nível da tensão entre facticidade e validade, agora situada no próprio poder político, a questão da legitimação de um poder político estruturado na forma do Estado de direito pode ser compreendida desde que, por intermédio da ótica do conceito de autonomia política dos cidadãos. A contribuição do poder político para a função intrínseca do direito (estabilizar expectativas de comportamento) consiste 
na geração de uma certeza jurídica, que possibilita aos destinatários do direito calcular as consequências de seu comportamento e dos outros. As normas jurídicas, em termos gerais, devem regular as circunstâncias, as situações de fato, aplicando a sua subsunção de forma imparcial. Esses requisitos são compreendidos à luz de uma codificação (atividade jurisprudencial), que proporciona normas jurídicas altamente consistentes.

\section{Referências}

CHAMON J. Lúcio Antonio. Filosofia do direito na alta modernidade: incursões teóricas em Kelsen, Luhmann e Habermas. Rio de Janeiro:

Lúmen Júris, 2005.

DURÃO, Aylton Barbieri. A tensão interna entre facticidade e validade no direito segundo Habermas. In: MARTINS, Clélia Aparecida; POKER, José Geraldo. (Org.). O pensamento de Habermas em questão. Marília: Oficina Universitária Unesp, 2008.

HABERMAS, Jürgen. Teoría de La acción comunicativa: racionalidad de la acción y racionalización social. T. I. [s.n.]: [S.l.], 2010.

. Direito e democracia: entre facticidade e validade I. 2 .

ed. Tradução de Flávio Beno Siebeneichler. Rio de Janeiro: Tempo Brasileiro, 2003a.

. Direito e democracia: entre facticidade e validade II. 2. ed. Tradução de Flávio Beno Siebeneichler. Rio de Janeiro: Tempo Brasileiro, 2003b.

. Pensamento pós-metafísico: estudos filosóficos. Tradução de Flávio Beno Siebeneichler. Rio de Janeiro: Tempo Brasileiro, 1990a.

. O discurso filosófico da modernidade. Tradução de Manuel José Simões Loureiro. Lisboa: Dom Quixote. 1990b.

. Teoría de La acción comunicativa: crítica de la razón funcionalista. Tomo II. Madrid: Taurus 1987.

MOREIRA, Luiz. Fundamentação do direito em Habermas. Belo Horizonte: Mandamentos, 1999. 
PIZZI, Jovino. Desafios Éticos e Políticos da Cidadania: ensaios de ética e filosofia política II. Ijuí: Unijuí. 2006.

SCHUMACHER, Aluisio Almeida. Comunicação e Democracia: fundamentos pragmático-formais e implicações jurídico-políticas da teoria da ação comunicativa. 2000. 245 f. Tese (Doutorado em Ciências Política) - Departamento de Ciências Política do Instituto de Filosofia e Ciências Humanas da Universidade Estadual de Campinas. Campinas, 2000 .

\section{SILVA, Luciano Braz. Considerações de Jürgen Habermas para} a filosofia do direito do século XXI: os limites e possibilidades da democracia, do estado democrático de direito e, dos direitos humanos. 2013. Fls. 275. (Dissertação - Mestrado em Filosofia do Direito) Mestrado em Direito. Centro Universitário Eurípides de Marília. Marília, 2013.

. O reconhecimento no Estado Democrático de Direito:

perspectivas da filosofia de Habermas para efetividade da Democracia e dos Direitos Humanos. Revista Direito Práxis, Rio de Janeiro, v. 4, n. 7, p. 122-152, 2013.

. Estado democrático de direito, direitos humanos e democracia: perspectivas racional-discursivas no pensamento de Habermas. Revista Direito Mackenzie, São Paulo, v. 6, n. 2, p. 230-250, 2012.

A ética no direito: iniciação científica (Filosofia do direito). São Paulo, SP: Fundação de Amparo Pesquisa do Estado de Paulo (FAPESP), 2008.

POKER, José Geraldo A. B. A democracia e o problema da racionalidade. In: MARTINS, Clélia Aparecida; POKER, José Geraldo. (Org.).

O pensamento de Habermas em questão. Marília: Oficina Universitária Unesp, 2008.

POZZOLI, Lafayette. Maritain e o Direito. São Paulo: Loyola, 2001. 
Samyra Naspolini Sanches é doutora em Direito pela Pontifícia Universidade Católica de São Paulo, mestre em Direito pela Universidade Federal de Santa Catarina e professora do mestrado em Direito da Universidade Nove de Julho e da Universidade de Marília.

E-mail: samyranaspolini@gmail.com.

Endereço profissional: Universidade Nove de Julho, Centro de Pesquisa em Direito, Rua Francisco Matarazzo, n. 612, Agua Branca, São Paulo, SP. CEP: 16015-270.

Luciano Braz da Silva é professor de Direito Constitucional na Universidade do Oeste Paulista e de Direito Constitucional e Filosofia do Direito na Faculdade de Ensino Superior e Formação Integral-Faculdade de Ensino Superior do Interior Paulista, advogado, e mestre em Filosofia do Direito pelo Centro Universitário Eurípides de Marília.

E-mail: brazadvogadoluciano@gmail.com

Endereço profissional: Universidade do Oeste Paulista, Rua José Bongiovani n700, Cidade Universitária, Presidente Prudente. SP. Brasil. CEP: 19050-920. 